\title{
Estimation of Cloud Effect on Solar Irradiance for Nigeria
}

\author{
M.J. Na-Allah ${ }^{1},{ }^{*}$ M.H. Ali ${ }^{2}$, and R.S. Said ${ }^{3}$ \\ ${ }^{1}$ School of Theoretical Physics, National Mathematical Centre, Abuja Nigeria \\ ${ }^{2}$ Department of physics, Bayero University, Kano Nigeria \\ ${ }^{3}$ Department of physics, Bayero University, Kano Nigeria
}

\begin{abstract}
The solar radiation is the fundamental source of energy that drives the Earth's climate and sustains life. The variability of this output certainly affects our planet. In the last two decades an enormous advance in the understanding of the variability of the solar irradiance has been achieved. Due to high need of solar power generation and inadequate solar radiation data, the prediction of the incoming solar energy is receiving more attention. Measured solar irradiances are sourced from six different locations through the Centre for Atmospheric Research, National Space Research and Development Agency, Ayingba Nigeria. Clear day solar irradiance equations are used to estimate the solar irradiances of the six measuring centers. The blocking effects of the cloud are estimated for each location from the measured and the calculated solar irradiances. The results show that Yola station has the lowest cloud absorption effect of about $114.5293 \mathrm{~W} / \mathrm{m}^{2}$ during the month of October while Lagos station has the highest cloud absorption effect of about $903.3042 \mathrm{~W} / \mathrm{m}^{2}$ during the month of January. Better design of solar application device can be obtained with the help of these values of the cloud effect.
\end{abstract}

\section{Introduction}

The growing populations of the world, the fast depleting reserves of fossil fuels, and the awareness of environmental impact have led the researchers to think of alternate sources of energy for a safer life on this earth. Therefore, the whole world is looking for non-exhaustible and renewable energy sources for their future. Among all the renewable energy sources, solar energy is the best option if it can be used in a cost effective manner; because the technology is also environmentally sound (Korachagaon, 2012 and Medugu, 2013). As the solar energy intercepted by the earth in one year is ten times greater than the total fossil resources including undiscovered and unexplored reserves, it is expected that the present world-wide research and development programs on solar energy would help to solve the future energy crisis of the world. Solar energy occupies one of the most important places among the various possible alternative energy sources. An accurate knowledge of solar radiation distribution at a particular geographical location is of vital importance for the development of many solar energy devices and for estimates of their performances (Chibani and Chegaar, 2000).

Unfortunately, for many developing countries, solar radiation measurements are not easily available for not being able to afford the measurement equipment and techniques involved. Several empirical models have been developed to calculate global solar radiation using various climatic parameters. These parameters include extraterrestrial radiation, sunshine hours, mean temperature, maximum temperature, soil temperature, relative humidity, number of rainy days, altitude, latitude, total precipitation, cloudiness and evaporation. The most commonly used parameter for estimating global solar radiation is sunshine duration (Jamil, 2010). However, Clouds are the most important regulator of solar radiation. By reflecting incoming solar radiation back to space, they cool the Earth atmosphere system - the so-called cloud albedo effect (Qiang, 2003).As is the case with wind, the solar resource at the ground level is highly variable mostly due to cloud cover variability (Inman, 2013).

The availability of solar radiation on the earth's surface is a function of geographical zone. The regions lying between $15^{\circ}$ and $35^{\circ}$ latitude north and south respectively seem to be most favourably located. They have relatively little rains and clouds so that over $90 \%$ of the incident sunshine is direct radiation and the yearly sunshine hour is usually over 3000hours. The next most favorable region is the equatorial belt from $15^{\circ} \mathrm{S}$ to $15^{\circ} \mathrm{N}$ which receives about 2300hours of sunshine per year with very little seasonal variation (Nwokoye and Okonkwo 2011). The high humidity and frequent clouds in this belt generally result in a high proportion of the solar radiation taking the form of scattered radiation. In general, total solar radiation (insolation) increases with latitude (Akinbode, 1992).

According to Salcedo et al; (2014) sunshine duration, air temperature and relative humidity are the most widely used meteorological parameters to predict daily solar radiation and its components. All these parameters are well correlated with the daily solar global radiation (Yacef et al; 2012). Over the years, many

*Corresponding author email: alim@buk.edu.ng 
models have been proposed to predict the amount of solar radiation using various parameters. Some works used the sunshine duration (Okonkwo et al; 2011, Okeke and Ugwuoke, 2012, and Oladosu et al; 2012), others used mean daytime cloud cover or relative humidity and maximum and minimum temperature (Chiemeka, 2008), while others used the number of rainy days, sunshine hours and a factor that depends on latitude and altitude (Huang et al; 2014). Artificial neural network (ANN) was used by Ibeh et al; (2012) at Minna and in their another work of similar approach at Uyo(Ibeh et al; 2012) for the estimation of global solar radiation. Other statistical models have also been used (Muhammad et al; 2015 and Said et al; 2015).

In this work, we made use of the data from six different locations obtained through the Centre for Atmospheric Research, National Space Research and Development Agency, Ayingba Nigeria to estimate the absorption effect of solar irradiance by comparing the measured solar irradiance and the calculated one

\section{The earth's orbit}

\section{Theoretical Background}

The earth revolves around the sun in an elliptical orbit, making one revolution every 365.25 days. The eccentricity of the ellipse is small and the orbit is, in fact, quite nearly circular. The point at which the earth is nearest the sun, the perihelion, occurs on January 2, at which point it is a little over 147 million kilometers away. At the other extreme, the aphelion, which occurs on July 3, the earth is about 152 million kilometers from the sun. This variation in distance is described by the following relationship:

$d=1.5 \times 10^{8}\left\{1+0.017 \sin \left[\frac{360(n-93)}{365}\right]\right\} \mathrm{km}$

Where $n$ is the day number, with January 1 as day 1 and December 31 being day number 365. Each day, as the earth rotates about its own axis, it also moves along the ellipse. If the earth were to spin only $360^{\circ}$ in a day, then after 6 months time our clocks would be off by 12 hours; that is, at noon on day 1 it would be the middle of the day, but 6 months later noon would occur in the middle of the night. To keep synchronized, the earth needs to rotate one extra turn each year, which means that in a 24-hour day the earth actually rotates $360.99^{\circ}$, which is a little surprising to most of us

\section{Solar declination}

The angle formed between the plane of the equator and a line drawn from the center of the sun to the center of the earth is called the solar declination, $\delta$. It varies between the extremes of $\pm 23.45^{\circ}$, and a simple sinusoidal relationship that assumes a 365 -day year and which puts the spring equinox on day $\mathrm{n}=284$ provides a very good approximation.

$\delta=23.45 \sin \left[\frac{360(284+\mathrm{n})}{365}\right]$

\section{Solar position at any time of day}

The location of the sun at any time of day can be described in terms of its altitude angle $\beta$ and its azimuth angle $\varphi_{\mathrm{s}}$. The subscript $\mathrm{s}$ in the azimuth angle helps us remember that this is the azimuth angle of the sun. By convention, the azimuth angle is positive in the morning with the sun in the east and negative in the afternoon with the sun in the west.

Equations of solar angles:

$\beta_{N}=90-L+\delta$

$\sin \beta=\cos L \cos H+\sin L \sin \delta$

$H=\frac{15^{0}}{\text { hour }}$ or $H=\frac{-15^{0}}{\text { hour }}$

Equations of clear sky insulation:

$I_{B}=A e^{-k m}$

$A=1160+75 \sin \left[\frac{360}{365}(n-275)\right]\left(W / m^{2}\right)$

$k=0.174+0.035 \sin \left[\frac{360}{365}(n-100)\right]$

$m=1 / \beta$

For the purpose of calculations, it is important to always remember that the hour angle $\mathrm{H}$ in equation (2.5) takes positive value in the morning (before solar noon) and negative in the evening (after solar noon). 
Where $\beta=$ solar altitude angle, $\beta_{\mathrm{N}}=$ altitude angle at solar noon, $\mathrm{L}=$ latitude, $\delta=$ solar declination, $\mathrm{I}_{\mathrm{B}}=$ beam insulation at earth's surface, $\mathrm{A}=$ Apparent extraterrestrial solar insulation, $\mathrm{k}=$ atmospheric optical depth and $\mathrm{m}$ = air mass ratio (Masters, 2004).

\section{Method}

The experimental location is Mussa Mosque (Old Site) Bayero University, Kano (at Latitude: 11.9785 and Longitude: 8.4783). The experiment involved measuring of solar irradiance during the sunshine hours using a pyrheliometer (510 Solar Meter) which measures the incident solar radiation (Direct radiation) in W/m $\mathrm{m}^{2}$ and the readings were taken at hourly intervals from 08.00 hours to 17.00 hours each day during the four days the experiment lasted.

Experimental measurements (Data) available were procured from six different locations through the Centre for Atmospheric Research, National Space Research and Development Agency, Federal Ministry of Science and Technology, Anyigba, Nigeria. From each of the six stations, a 5minutes interval of data for the direct solar irradiance was obtained throughout. Some details about the places and the length of the data are given in the map of Nigeria and table 1 as well. The preliminary experimental test conducted in Kano at Bayero University was to test the theoretical relationship with experimental results. Next, was the prediction of the solar irradiance for the four days measured in the preliminary experiment at the same latitude using the formula (for a clear day solar irradiance). The cloud effect on the solar irradiance was determined by finding the difference between the predicted and average monthly-hourly measured values (blocked irradiance). Finally, the estimated solar irradiance was modified by adding the difference to each measured value based on the latitude site and day number. Three results were obtained and plotted for comparison - the experimental measurements, the predictions as well as the modifications.

These four days (precisely $19^{\text {th }}$ Nov to $22^{\text {nd }}$ Nov i.e. day 323 to day 326 ) were chosen from each station in the experimental measurements depending on the year available from the data obtained, and the respective solar irradiances for each of the measuring locations was computed using equation (2.2) through (2.8) by considering their different geographical locations (latitudes and longitudes). This procedure was repeated for each station and the comparison was also made for the three results at each site.

Table 1: Site description and data duration

\begin{tabular}{|l|l|l|l|l|l|}
\hline S/No & Station & Latitude & Longitude & \multicolumn{2}{|l|}{ Duration } \\
\cline { 4 - 6 } & & & & from & To \\
\hline 1 & Abuja & 8.9957 & 7.16825 & 2007 & 2012 \\
\hline 2 & Ayingba & 7.4840 & 7.1874 & 2010 & 2013 \\
\hline 3 & Lagos & 6.5193 & 3.3920 & 2007 & 2008 \\
\hline 4 & Makurdi & 7.7226 & 8.5562 & 2008 & 2011 \\
\hline 5 & Minna & 9.6597 & 6.5268 & 2008 & 2011 \\
\hline 6 & Yola & 9.1967 & 12.4995 & 2009 & 2013 \\
\hline
\end{tabular}

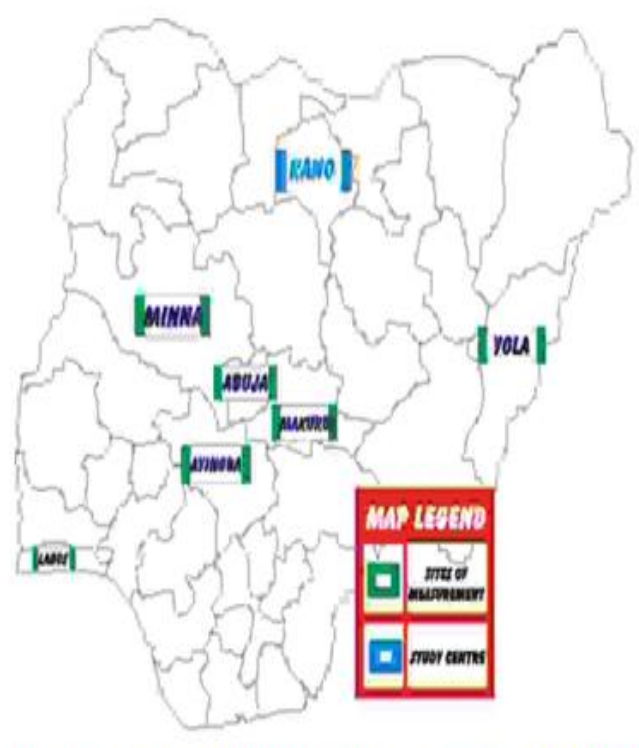

Figure 1: Map of Nigeria showing the six measuring stations including the study area (Kano)

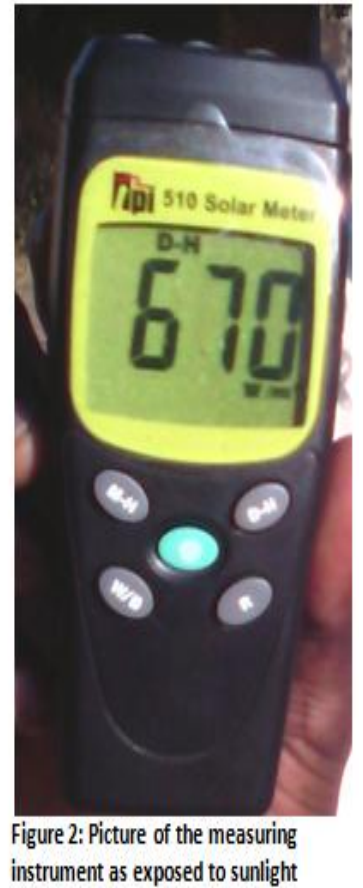

instrument as exposed to sunlight 


\section{Results and discussion}

The resultsofthe three sets of data(measured, Calculated and modified) are presented in this section for each measuring station including Kano (the study centre) in graphs.
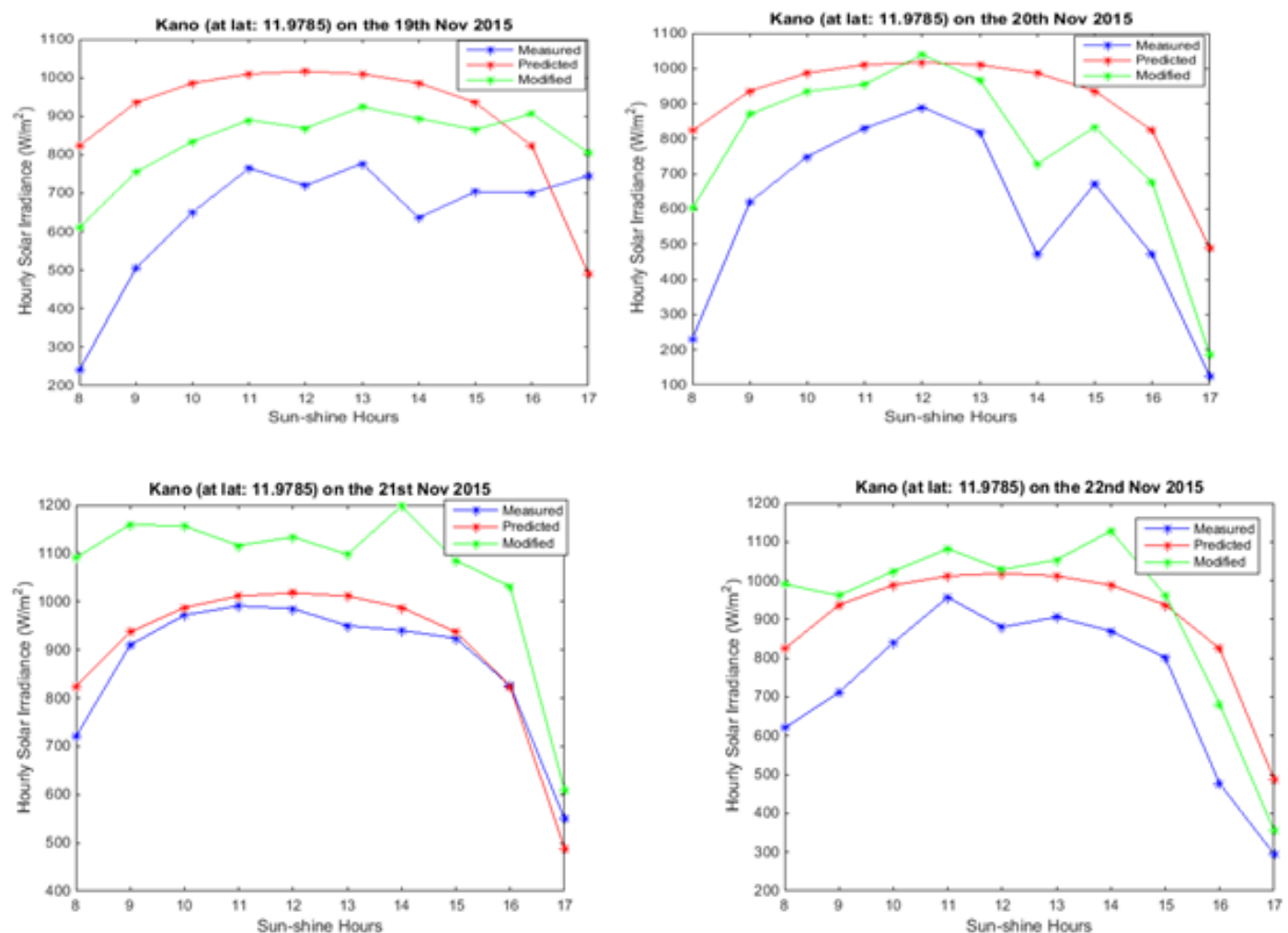

Figure 3: Solar Irradiance Plotted against the Daily Sun-Shine Hours for both measured and predicted values of the irradianceatBUK, Kano (at latitude: 11.9875 longitude: 8.4783).

The solar irradiance recorded during the preliminary test at Bayero University Kano gave a clear understanding of the power of the equations employed in this research. It is obvious that the 'third day' $\left(21^{\text {st }}\right.$ day of November 2015) was noted to be very clear in the sky and free from dust and other environmental issues, consequently (in Figure 3) the two results for the predicted and the measured data merges at most of the times during the day. However, the curve for the modified estimation is much higher than the original estimation (prediction) - this shows that the estimation on this very day at this point of latitude does not need any modification. Similarly on the 'fourth day' $\left(22^{\text {nd }}\right.$ November 2015$)$, the modification is not much significant since it agrees mostly with the original prediction. The other two days experienced dust storms, causing the measured irradiance to show abnormal trends indicating that, in the absence of these dusts, clouds, aerosols and other environmental pollutants in the atmosphere, the values predicted by this work would be equally measured accordingly. However, the modification is very useful in this case since it appears mid-way between the estimated and the measured values.

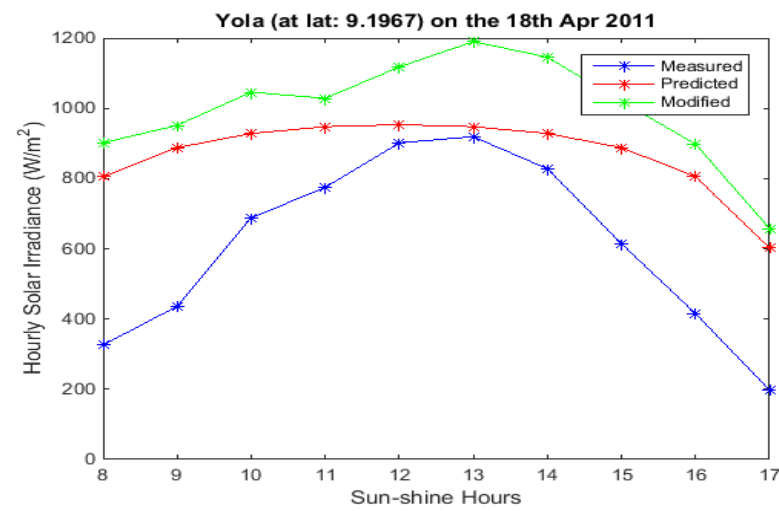



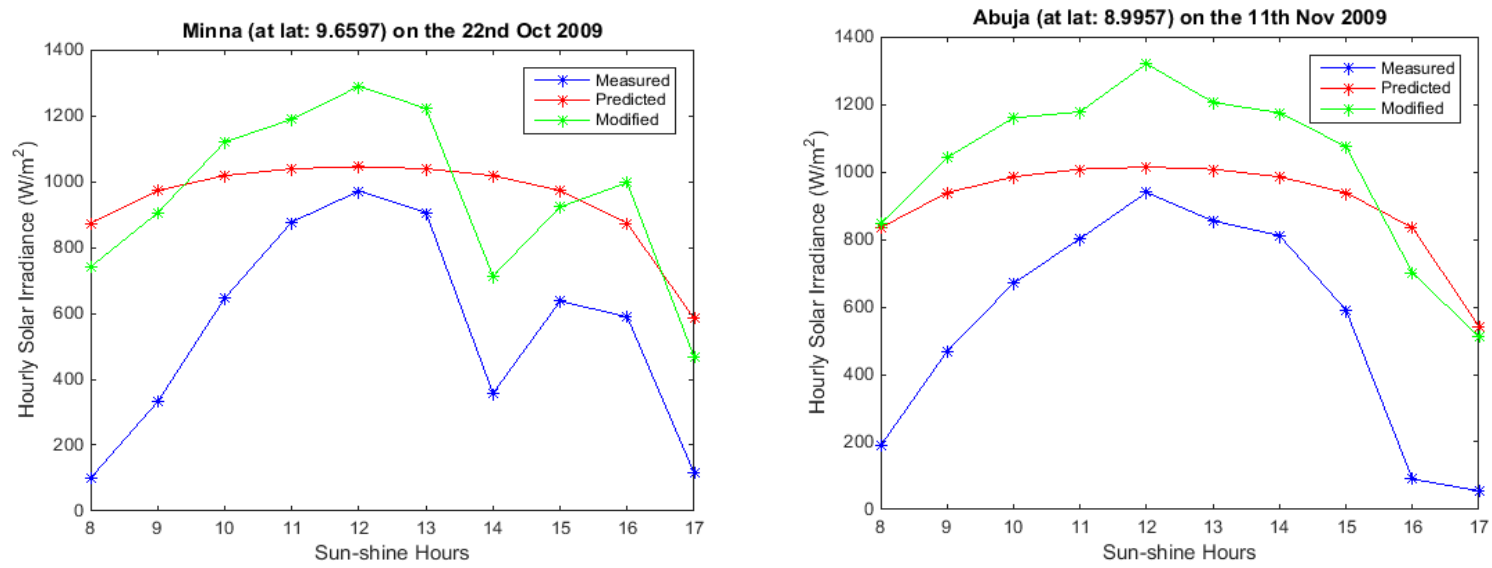

Figure 4: Solar Irradiance Plotted against the Daily Sun-Shine Hours for both measured and predicted values of the irradiance, for the stations randomly selected from different sites within Nigeria.

Three graphs from (Figure 4) were chosen randomly from different locations at different latitudes and in different years. In each of the graphs there are some times of the day when the predicted values agree closely with the measured data. This could be because the dusts and aerosols were not much loaded in the atmosphere, and the irradiance was not affected by cloud blockage. This further validates the relationship of computing clear sky irradiance being used in this work.
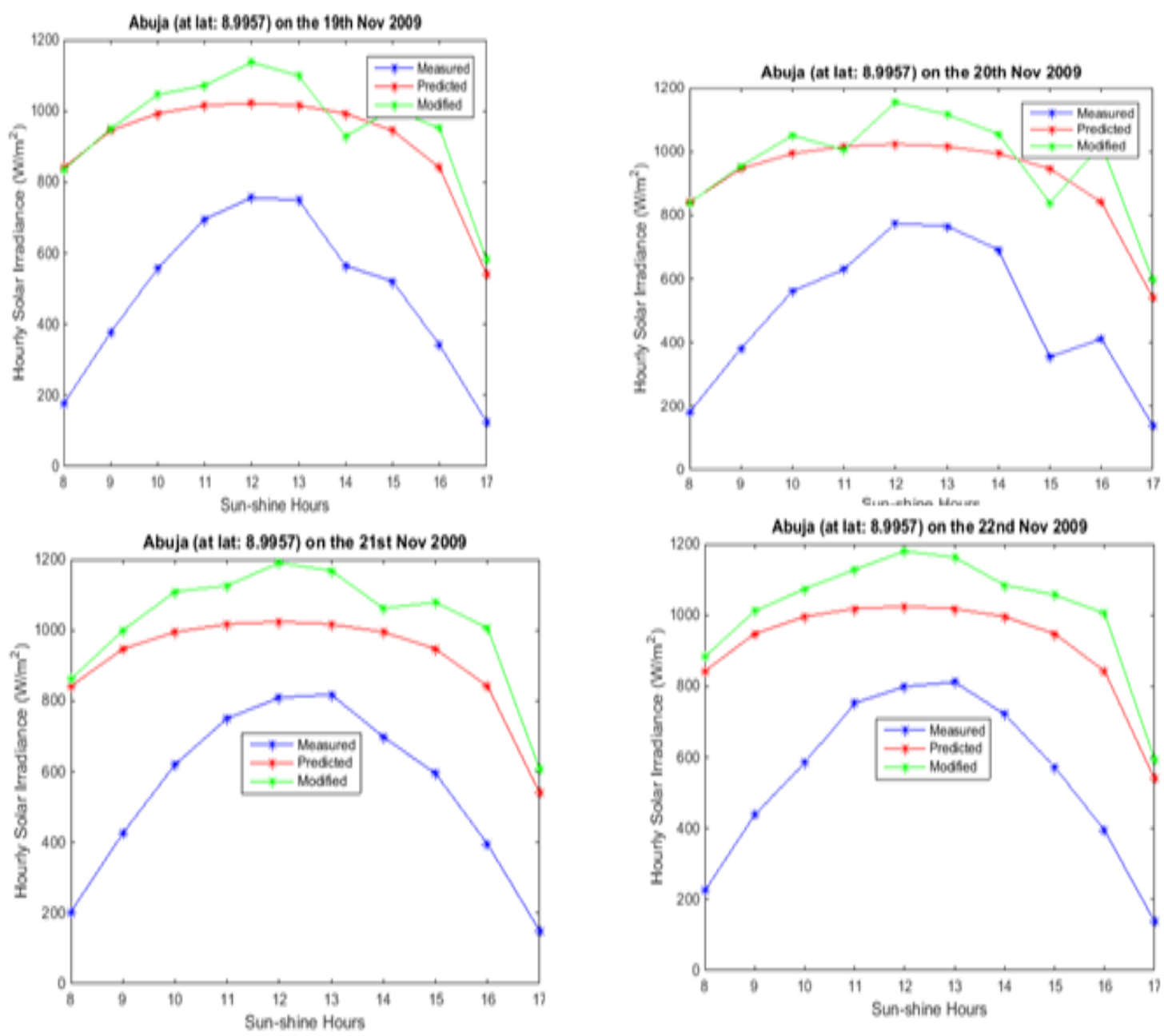

Figure 5:Solar Irradiance Plotted against the Daily Sun-Shine Hours for both measured and predicted values of the irradiance at Abuja ( Latitude: 8.9957 longitude: 7.16825). 

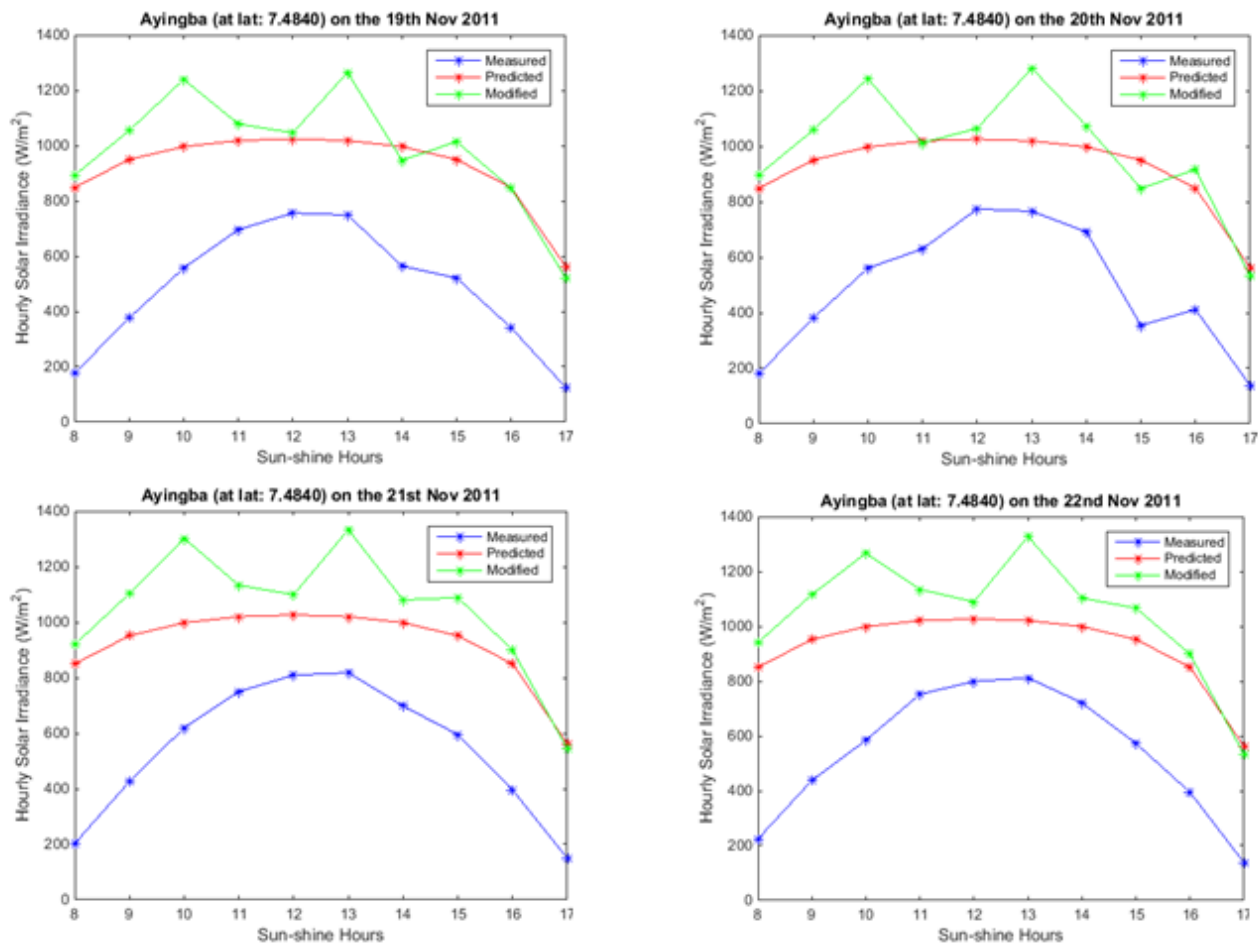

Figure 6: Solar Irradiance Plotted against the Daily Sun-Shine Hours for both measured and predicted values of the irradiance at Ayingba (Latitude: 7.4840 longitude:7.1874).

The graphs on the $21^{\text {st }}$ November in Abuja 2009 (Figure 5) and Ayingba 2011 (Figure 6) show an irregularity in the pattern of the measured data unlike the remaining days. This could be due to the presence of heavy clouds and or aerosols loading in the atmosphere, since on the other days when probably there were clear skies, the solar irradiance assumed its usual trends. The fact that the solar irradiance in the two different stations (despite difference in the year) followed almost similar pattern, is not quite surprising since the stations are not far away from each other. This also shows that the measurements were done accordingly and the data obtained is genuine from all the stations. Also the graphs show that, the modification is significant only in few hours at these latitudes during these day numbers.
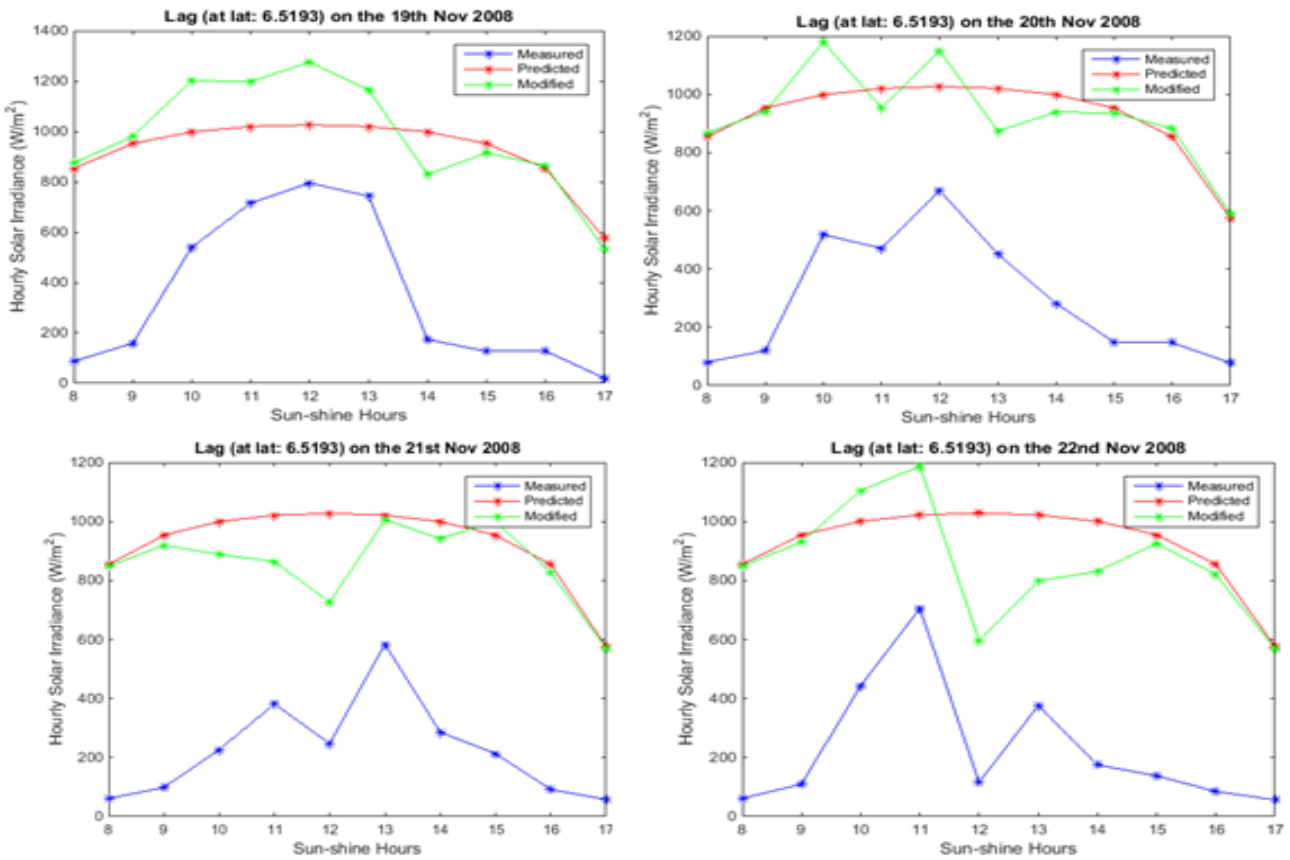

Figure 7: Solar Irradiance Plotted against the Daily Sun-Shine Hours for both measured and predicted values of the irradiance at Lagos (Latitude: 6.5193 longitude: 3.3920). 
The data measured in Lagos station did not show a specific trend to describe (Figure 7). However, the four graphs share a similar zig-zag pattern. This might be the consequence of clouds and dust. For similar reasons at this station, the solar irradiance has peak values by 1:00pm and 11:00am in some days instead of solar noon as expected. Interestingly for this latitude site, the estimations show high needs for modification because the computed values are much greater than the values measured.
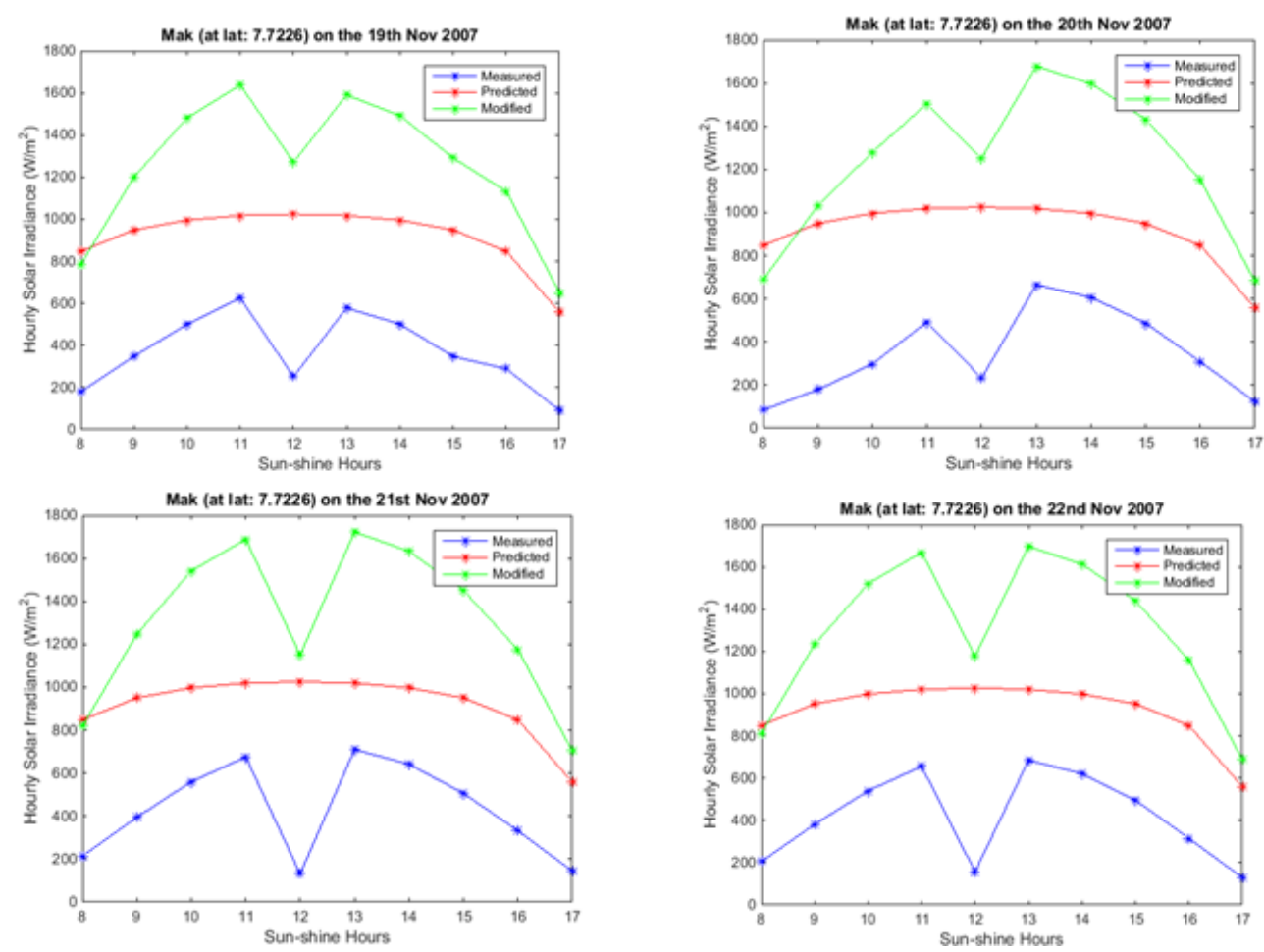

Figure 8: Solar Irradiance Plotted against the Daily Sun-Shine Hours for both measured and predicted values of the irradiance at Makurdi(Latitude: 7.7226 longitude: 8.5562)
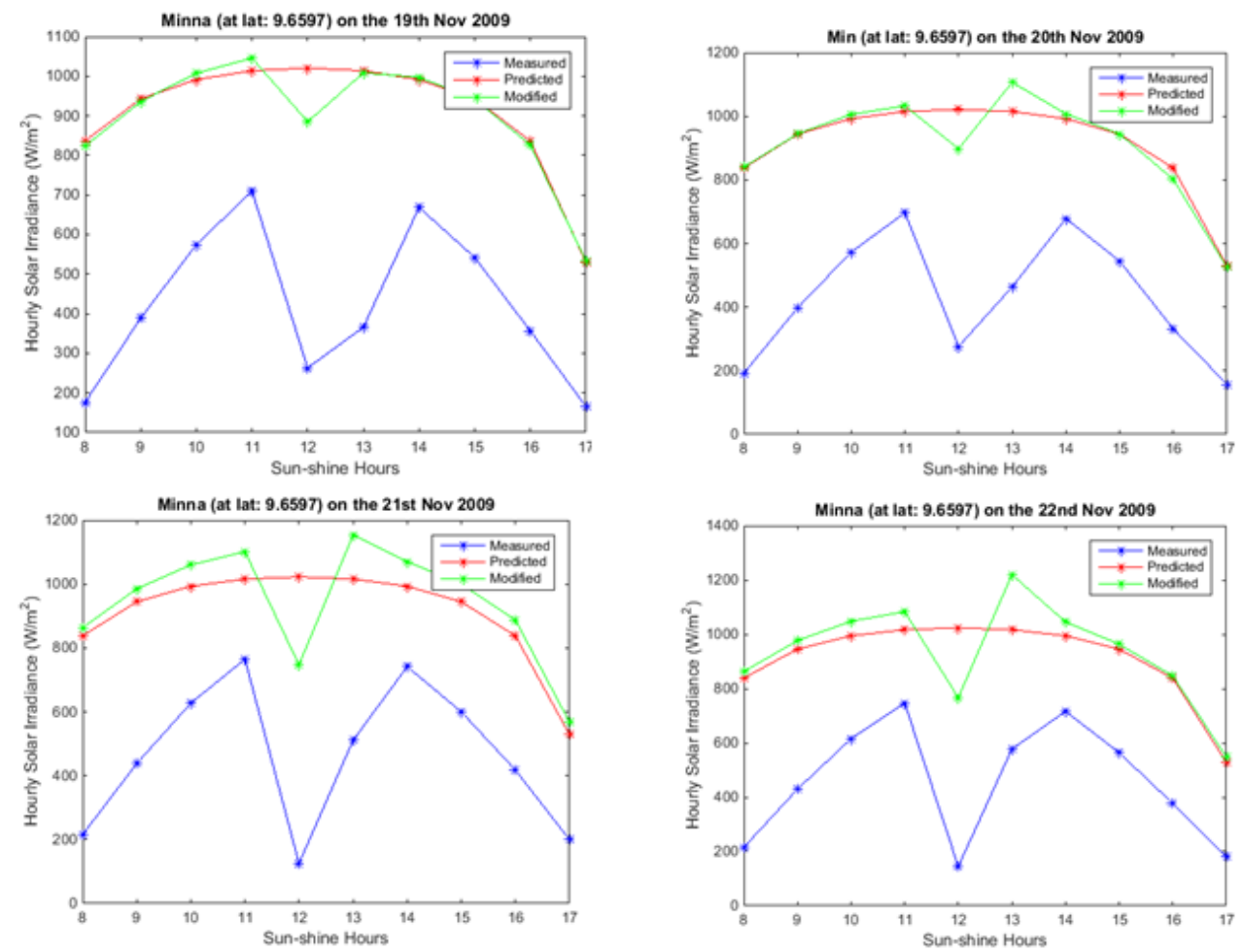

Figure 9: Solar Irradiance Plotted against the Daily Sun-Shine Hours for both measured and predicted values of the irradiance at Minna (Latitude: 9.6597 longitude: 6.5268). 
Figures 8 and 9 present the solar irradiance plotted against sun-shine hours in Makurdi and Minna respectively. These two figures describe different stations in the same zones. Consequently they show a similar pattern for the solar irradiance in all the four days captured from the data. Observations in Makurdi station indicate that in all the four graphs (figure 8), estimations are more preferable than the modifications whereas in Minna (Figure 9) the two results assumed same values at most of the times. This tells more about the validity and power of our modifications. It can be concluded that the solar radiation falling to a very low value at the two stations during solar noon is far below usual. Although, this could be attributed to the weather of the month of November since it is a dusty period, however it could also be a result of capricious clouds.
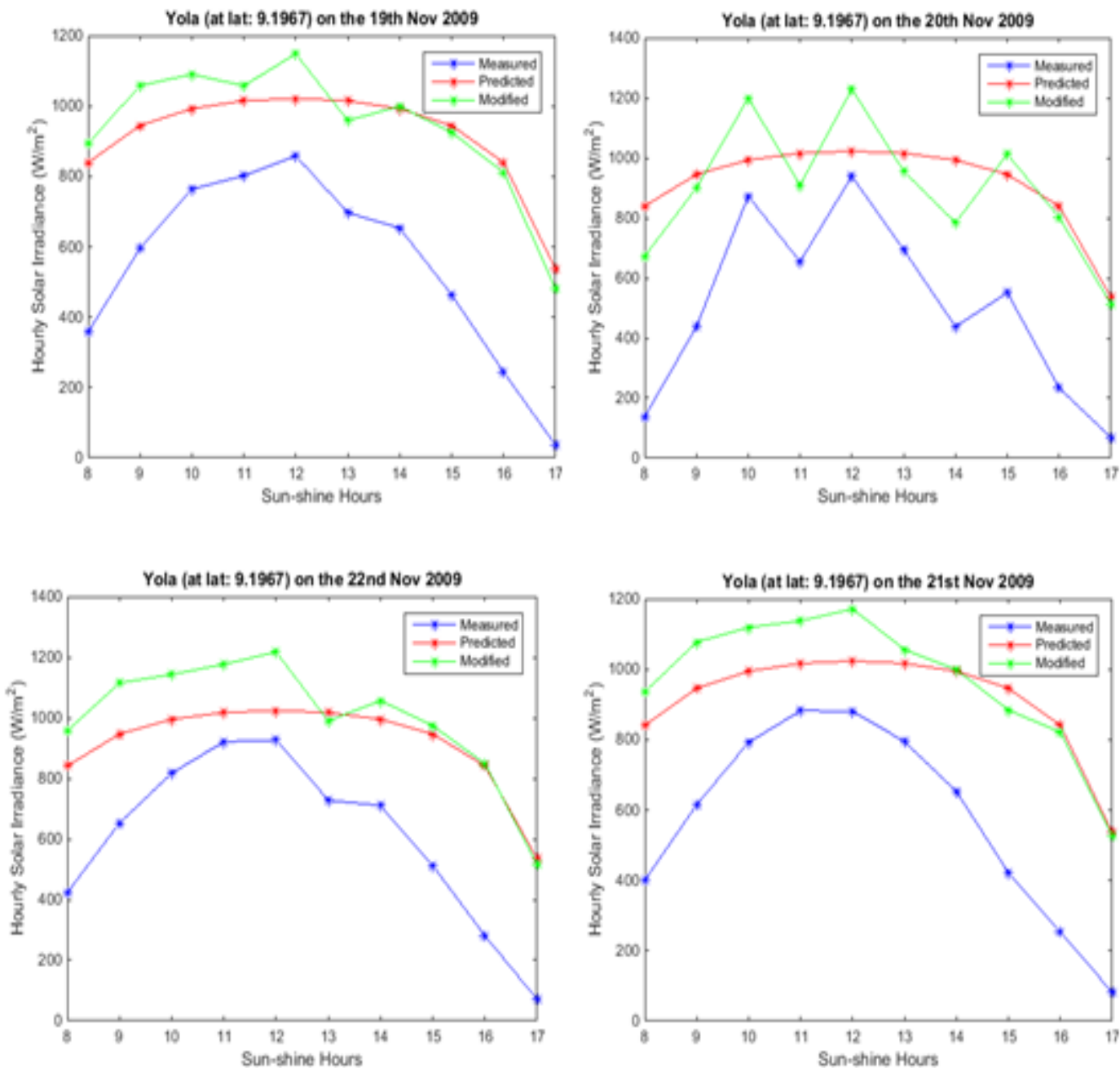

Figure 10: Solar Irradiance Plotted against the Daily Sun-Shine Hours for both measured and predicted values of the irradiance at Yola(Latitude: 9.1967 longitude: 12.4995)

At Yola station (Figure 10) throughout the four days selected, the values of the measured solar irradiance are seen to be much closer to the predicted values compared to other measuring centers. This shows that in this region there is high intensity of sunlight and less experience of clouds and dust storms. However, except on $20^{\text {th }}$ November modifications are accepted only for few hours during the four days presented. Generally, observations in all the stations show that the daily cloud absorption effect is more significant at sunrise and sunset which may be the results of increase in the air mass ratio.

\section{Conclusion}

We have found that Yola station has the lowest cloud absorption effect of about $114.5293 \mathrm{~W} / \mathrm{m}^{2}$ during the month of October by 12:00pm while Lagos station has the highest cloud absorption effect of about $903.3042 \mathrm{~W} / \mathrm{m}^{2}$ during the month of February by 9:00am. Now with this information there will be more realistic estimates of solar irradiance for all the locations studied; Kano, Abuja, Minna, Ayingba, Lagos, Makurdi and Yola.. Moreover, the effect of cloud on solar irradiance is clearly a location dependent. Thus, it is recommended that similar work should be carried out for each state of the 36 state of the federation. 


\section{References}

[1] Akinbode, F. (1992). Solar Radiation in Minna: Correlation with Meteorological Data. Nigerian Journal of Renewable Energy, 3(1), 9-17.

[2] Chibani A. and Chegaar M. (2000). A Simple Method for Computing Global Solar Radiation. Rev. Energ. Ren., 111-115.

[3] Chiemeka, I. U. (2008). Estimation of solar radiation at Uturu, Nigeria. International Journal of Physical Sciences, 3(5), 126-130.

[4] Huang J., Troccoli A., and Coppin P. (2014). An analytical comparison of four approaches to modelling the daily variability of solar irradiance using meteorological records. Renewable Energy, 72, 195-202. http://doi.org/10.1016/j.renene.2014.07.015

[5] Ibeh G.F, Agbo G. A. and Rabia S. (2012). Application of artificial neural network and Angstom-Prescot tmodels in prediction of global radiation of Uyo, Nigeria, with atmospheric parameters. Advances in Applied Science Research, 3(1), 619-624.

[6] Ibeh G.F, Agbo G.A, Rabia. S. and Chikwenze A. R. (2012). Comparison of emperical and artificial neural network models for correleation of monthly average global solar radiation with sunshine hours in Minna, Niger state, Nigeria. International Journal of Physical Sciences, 7(8), 1162-1950.

[7] Inman H., Pedro H., Hugo T. C., \& Coimbra C., F. M. (2013). Solar forecasting methods for renewable energy integration. Progress in Energy and Combustion Science, 39(6), 535-576. http://doi.org/10.1016/j.pecs.2013.06.002

[8] Jamil M., and Tiwari. G. N. (2010). Solar radiation models - review. International Journal of Energy and Environment, 1(5), 861870. http://doi.org/10.1002/er

[9] Korachagaon, and V. N. Bapat (2012). Development of a site-independent mathematical model for the estimation of global solar radiation on earth's surface around the globe. International Journal of Energy and Environment, 3(2), $295-304$.

[10] Masters, G. M. (2004). Renewable and effecient electric power systems. John Wiley \& Sons, Inc., Hoboken, New Jersey.

[11] Medugu. (2013). Solar radiation: Correlation between measured and predicted values in Mubi, Nigeria, 4(January), $11-17$. http://doi.org/10.5897/IJSTER11.056

[12] Muhammad B.G, Said, R.S and Najib, G. Y. (2015). Emperical models for the estimation of global solar radiation in Yola, Nigeria. Journal of the Nigerian Association of Mathematical Physics, 30, 153-160.

[13] Nwokoye, A. O. C and Okonkwo G. N. (2011). Measurement and Performance Analysis of Daily Avereage Solar Radiation at Awka, Nigeria. Journal of Basic Physical Research, 2(2), 7-13.

[14] Okeke C.E and Ugwuoke P.E. (2012). Statistical Assessment of Average Global and Diffuse Solar Radiation on Horizontal Surfaces in Tropical Climate. International Journal of Renewable Energy Research, (November), 269-273.

[15] Oladosu R., Adediji A. Ojo J., and Adegbite A. (2012). Daily averages of solar radiation measured at Iju , Nigeria in 2008. International Journal of Physical Sciences, 7(27), 5026-5035. http://doi.org/10.5897/IJPS11.377

[16] Qiang, F. U. (2003). Radiation (Solar). Elsevier Science, -(1981), 1859-1863.

[17] Said R.S, Gabriel F.I, Garba M. B. and Najib, G. Y. (2015). Variation of solar radiation and its correlation with weather parameters using statistical analysis at Yola. Journal of the Nigerian Association of Mathematical Physics, 29, 319-324.

[18] Salcedo S. S., Casanova M. C., Parto S. A. and Sanchez G. M. (2014). Daily global solar radiation prediction based on a hybrid Coral Reefs Optimization - Extreme Learning Machine approach. Solar Energy, 105, 91-98. http://doi.org/10.1016/j.solener.2014.04.009

[19] Yacef, R. Benghanem, M. and Mellit, A. (2012). Prediction of daily global solar irradiation data using Bayesian neural network: A comparative study. Renewable Energy, 48, 146-154. http://doi.org/10.1016/j.renene.2012.04.036 